\section{Distribution of Animals and Plants by Ocean Currents.}

I BEG to forward you herewith some extracts from a letter just received from Port Elizabeth, South Africa, which, I think, cannot fail to interest your readers in connection with Darwin's theory of the distribution of animals and plants in some cases by ocean currents. My correspondent writes :-

"About the beginning of the year 1887 the attention of the public of Port Elizabeth was aroused by finding a quantity of pumice-stone washed up upon the shores of the bay, showing volcanic action. Some of the pieces were c svered with barnacles of a few months growth, and others appeared as though a mass of vitrified matter had been poured upon them. At the same time, shipmasters stated that they had seen large masses floating upon the sea as they approached the east coast of Africa. Strange fish also made their appearance in our waters, and, among the number, two large specimens of the ox-ray species were found washed up upon the rocks. But more remarkable was the discovery of four venomous sea-snakes about 18 inches long, the bodies marked black above and yellow below, answering the description of the Pelamis bicolor usually to be found about the coasts of Sumatra, Java, and the adjacent isles, and which must have followed the floating debris. One of these snakes was still alive when found, although it did not long survive, and one of the others was in a sufficient state of preservation to be sent to the Museum. What will prove more interesting still, is the discovery of a large seed resembling a cocoa-nut, which was picked up about the same time, of which Mr. Russell Hallack, of Port Elizabeth, gives the following description :-

" " A bout the latter end of 1886 a large husky fruit was picked up. It resembled a square cocoa-nut of 4 inches cube, not quite so deep as broad and long. Inside this husk, which was more cork-like than fibrous, was a solitary nut, about $\mathbf{I} \frac{3}{4}$ inch round, melon-shaped, with fluted outside, covered with a coating resembling potato-peel. This nut had been bitten by the boy who found it, but whether the taste was not to his liking, or for some other reason, he was persuaded to give the remains to the gardener of the north-end park, who planted it. In due time the shoot came up like a potato-plant with small leaves. The plan is now about 4 feet high, and the small leaves have developed into grand foliage 20 inches long by 7 or 8 broad. It is sup posed to be the Barringtonia speciosa, a native of the Eas Indies. A smaller variety, the $B$. racemosa, is said to exist in $\mathrm{Natal}$ and the east crast of Africa, but is easily distinguished from this by the smallness of its fruit. The $B$. speciosa belongs to the myrtle tribe, but differs from the ordinary type in having this large, one-sided, corky husked fruit; it i- one of the handsomest of its tribe, and in the Moluccas attains the height of 40 or 50 feet, with a circumference of 10 to 14 feet. It is generally found near the sea.'"

The suggestion is that this nut, as well as the snakes, the strange fish, and the pumice-stone, are all relics of the great Krakatão eruption in $\mathbf{1} 88_{3}$, and that they had drifted about till the beginning of 1887 , till thrown upon the coast of South Africa. If this be really the case, the tenacity of life in the snakes and the nut is truly remarkable, and, as my correspondent adds: "Surely some of this debris must have been deposited on the island shores visited by these currents, and if we could only become acquainted with the date of their appearance upon each, some idea might be formed as to the course taken by these plants, \&c., in their journey to Southern Africa."

I find, by a reference to the back numbers of NATURE, that the pumice has been traced to the east coast of Africa, leaving portions on various islands en route, and that some of it was timed to reach the west cuast of America at Panama in I886, but nowhere do I find any notice, except that given above, $\mathrm{c}$ animal or vegetable debris accompanying the masses of pumice. Perhaps the publication of these interesting facts may call forth similar observations from some of the Pacific Islands.

\section{A. W. BUCKLAND.}

\section{Watches and the Weather.}

My neighbours, Messrs. Jacol, and Ross, watchmakers, often tell me their experiences in the breaking of mainsprings.

Unreflecting people fancy they have broken the spring by over-winding, or in other words have drawn asunder a piece of steel by the force of finger and thumb.

The springs of course break through a subtle molecular change produced in the steel by atmospheric causes: they usually fly asunder a few hours after being wound, at 3 or 4 o'clock in the morning. Many watches and clocks come to the workshops for new springs after a. frost, but not until a thaw has set in ; still more come after thunderstorms.

This morning a clock spring was taken out of its box, which had overstrained itself at one moment into seventeen pieces, there was a complete fracture in each coil along a radial line from the centre. Some time back one was found with three such radial lines of fracture.

Of course this subject is not new, but it gains by recorded experiences.

The College, Winchester, July 9.

\section{Preserving the Colour of Flowers.}

I SHOULD be greatly obliged if some of your readers would inform me how to preserve the colour of those flowers prone to fade during and after pressing.

In a local paper I saw an extract from the Pharmaceutical fournal, in which salicylic acid was recommended. I have tried it both as powder and in solution in spirit; in either case it had a great tendency-except in the case of yellow flowersto change the colour to either a bright scarlet or to a light brown. A. W.

[There is no difficulty in preserving the colour of yellow flowers if they are properly dried by the ordinary method, i.e. in absorbent paper, changed at the end of the first day, and once or twice afterwards. It is very difficult to prevent such plants as Pedicularis, Bartsia, and Melampyrum turning black. See an account of a plan recently tried in Germany by Schönland, in Annals of Botany, vol. i. p. I78, 1887.-J. G. BAKER.]

\section{THE LIFE STATISTICS OF AN INDIAN PROVINCE.}

SOME years ago, in this journal (vol. xxix. p. 338), I published a short article on the intimate relations which subsist between meteorological conditions and the statistics of death and crime in India. In this it was incidentally mentioned that, imperfect as they were, the vital statistics of the North-West Provinces and Oudh were at that time more to be depended on than those of any other province in India, thanks to the unremitting attention paid to the subject of registration by the late Sanitary Commissioner, Dr. Planck; and though they have not sensibly improved since 1884 , but perhaps rather fallen off in accuracy, the birth and death registers of these provinces are still undoubtedly better than any others in India embracing an equal population.

As ten complete years have now elapsed since the amalgamation of the two provinces, which together contain a larger population than any European country except Russia, and as similar statistics are not at present obtainable from any other Oriental country but India, it may be of interest to compare some of the conditions of life revealed by them with those obtaining in the more favoured countries of the West. That India has a high death-rate, owing to the unhealthiness of the prevailing climatic conditions and imperfect sanitation, as well as to the low vitality of the mass of the people consequent upon superabundant population and insufficient food, is universally understood; but there is no proper appreciation of the marvellous recuperative power of a population among whom prudential restraints on increase are unknown, and where almost every woman has been married in childhood, and commences to bear children at the age of fourteen or fifteen years. It may be said with almost absolute truth that there are not only no old maids in India, but no unmarried women above the age of puberty, except the unfortunate class of Hindu widows of the higher castes, who are not permitted to marry again ; but though this class appeals in many ways to our sympathies, it is of very slight importance from the point of view of the increase of population, the widows of child-bearing age amounting to only 9 per cent. of the 
total number of females of the same age--a proportion which compares very favourably with that of widows and spinsters in England. This wonderful power of rapid recovery after decimation by famine or pestilence will be fully exhibited in the tables given below.

The registration of deaths was in regular operation for several years, both in the North-West Provinces and in Oudh, before the two were united under one administration in 1877 . That of births was first introduced generally in 1879 , though it had been tentatively commenced in municipalities and cantonments some time previously. We have therefore now (February i 888 ) ten complete years' death statistics for the united provinces, of a fairly uniform degree of accuracy, and nine years' registers of births, decidedly improving in completeness and accuracy for the first five or six years. The births for the first year of the ten-1 $878-$ may also be approximately arrived at by a proportionate computation from those registered that year in municipalities. The total number of births of each sex, registered in each of the ten years, was as follows :-

\begin{tabular}{ccr} 
Year. & & \multicolumn{1}{c}{ Males. } \\
1878 & $\ldots$ & $667,975^{*}$ \\
$\mathbf{1} 879$ & $\ldots$ & $669,92 \mathbf{1}$ \\
1880 & $\ldots$ & 747,953 \\
1881 & $\ldots$ & 948,191 \\
1882 & $\ldots$ & 875,616 \\
1883 & $\ldots$ & 950,932 \\
1884 & $\ldots$ & $1,015,699$ \\
1885 & $\ldots$ & 957,672 \\
1886 & $\ldots$ & 874,099 \\
J887 & $\ldots$ & 902,844 \\
Total & \multicolumn{2}{c}{$8,610,902$}
\end{tabular}

\begin{tabular}{|c|c|c|c|}
\hline & Females. & & $\begin{array}{l}\text { No. of Males } \\
\text { roo F emales. }\end{array}$ \\
\hline ... & $54 \xi, 285^{*}$ & $\ldots$ & 122.50 \\
\hline & $555,9 \mathrm{II}$ & $\ldots$ & $\mathrm{I} 2 \mathrm{O}^{\circ}{ }_{5} \mathrm{I}$ \\
\hline & 642,826 & $\ldots$ & $116 \cdot 34$ \\
\hline . & $8_{3} \mathrm{I}, 282$ & $\ldots$ & 11406 \\
\hline & 780,543 & $\ldots$ & II $2 \cdot 18$ \\
\hline & 850,469 & $\ldots$ & I I I $8 \mathrm{r}$ \\
\hline & 915,262 & $\ldots$ & 110.98 \\
\hline & $86 \mathrm{r}, 609$ & $\ldots$ & III 15 \\
\hline & 785,433 & $\ldots$ & $111 \cdot 28$ \\
\hline & $805,89 \mathrm{r}$ & $\cdots$ & $\mathrm{I} 12{ }^{\circ} \mathrm{O} 3$ \\
\hline & $574,5 \mathrm{II}$ & $\ldots$ & 113.68 \\
\hline
\end{tabular}

An inspection of the last column shows that these numbers require to be corrected, not only by an allowance for general incompleteness of the records, but by a special addition to counteract the tendency to omit females. During the first seven years this tendency diminished as registration improved, and the numbers of the two sexes approximated more and more to equality; but even with the most intelligent and careful recording agency, the true ratio between the sexes at birth will never be attained in the records until the opinion of the mass of the people on the relative values of male and female life has undergone a complete alteration. The ratios for the first seven or eight years in the table give a curve apparently asymptotic to a certain line, the ordinate of which would stand for the ratio attainable by the greatest care in registration under the present conditions. Representing the abore ratios for the first eight years by the formula, $a+\frac{b}{t}$, where $t$ is counted in years from 1877 , we find the ordinate of the asymptote, $a$, to be 108.57 . In the provinces there are, however, two districts in which the numbers born of the two sexes invariably approach much more nearly to equality. One is Garhwál, a Himalayan district inhabited by an unsophisticated people who claim to be Rájpits, but are probably of aboriginal descent, and who have never come under Muhammadan influence in any way, or acquired the custom of paying a heavy dowry with the bride, which is the cause of female infanticide among many of the higher castes. The other is Lalitpur, in the extreme south, where the inhabitants are chiefly Chamárs and other low castes, who have never concealed their women or practised infanticide, and amongst many of whom the bridegroom's family pay for the bride. The statistics for these two districts give a series of ratios represented by a curve whose asymptote has an ordinate of $100 \cdot 00$, or which points ultimately to exact equality between the sexes. In like manner, if we select for each year that district in which the recorded birth-rate was

\footnotetext{
* Estimated from thcse registered in municipalities.
}

highest, and where, therefore, the registration was presumably most complete, we get a curve pointing to an ultimate ratio of 10278 males to roo females. If we take the mean of all three results, that for Garhwál and Lalitpur being probably below the true average for the whole population, we get I0378 males to Ioo females. This comes very near the ratio for England, which, I believe, is between $\mathrm{IO}_{3}$ and 104 , and is almost identical with that deduced from the distribution of the population according to age and sex at the last two censuses of the North-West Provinces-namely, I0375. It may therefore be adopted as a close approximation to the truth, and it shows that, in regard to the relative numbers of the sexes, human nature is much the same in the East and West, notwithstanding the deceptive appearance presented by unanalyzed statistics, as well as by public gatherings in countries where respectable women seldom venture out of doors.

The numbers of females in the above table must therefore be all recast so as to give 10378 males for every Ioo females.

This special inaccuracy in the birth tables being corrected, there remains the general inaccuracy due to incompleteness of the register, which is common to both births and deaths, and has been estimated by Dr. Planck, after careful and extended personal inquiry, at 20 per cent. of the total, ar one-fourth of the numbers recorded. When both causes of error are allowed for, the total number of births in each year will be as in the second column of the next table. The third column gives the recorded deaths, increased by 25 per cent. to make them represent approximately the true mortality, and the last shows the increase or decrease of population each year, due to these causes. The figures in this column represent very fairly the total gain or loss of population, for the number of emigrants is only three or four thousand annually, and this loss is partly balanced by a return migration, the numbers of which are not known.

$$
\begin{aligned}
& \begin{array}{ccccccc}
\text { Year. } & & \text { Births. } & & \text { Deaths. } & & \text { Increase. } \\
\text { I878 } & \ldots & \text { I,639,544 } & \ldots & \text { I,902,175 } & \ldots & -262,631
\end{array} \\
& \begin{array}{lllllll}
1879 & \ldots & 1,644,320 & \ldots & 2,393,124 & \ldots & -748,804
\end{array} \\
& \begin{array}{lllllll}
1880 & \ldots & 1,835,850 & \ldots & 1,601,544 & \ldots & +234,306
\end{array} \\
& \begin{array}{llllllll}
\mathbf{1} 88 \mathrm{I} & \ldots & 2,327,335 & \ldots & \mathbf{1}, 753,09 \mathbf{I} & \ldots & +574,244
\end{array} \\
& \begin{array}{lllllll}
1882 & \ldots & 2,149,219 & \ldots & 1,856,409 & \ldots & +292,810
\end{array} \\
& \begin{array}{lllllll}
1883 & \ldots & 2,334,062 & \ldots & 1,520,371 & \ldots & +813,691
\end{array} \\
& \begin{array}{llllllll}
1884 & \ldots & 2,493,036 & \ldots & 1,944,177 & \ldots & +548,859
\end{array} \\
& \begin{array}{llllllll}
1885 & \ldots & 2,350,606 & \ldots & \text { r,763,299 } & \ldots & +587,307
\end{array} \\
& \begin{array}{lllllll}
1886 & \ldots & 2,145,476 & \ldots & 1,834,516 & \ldots & +310,960
\end{array} \\
& \begin{array}{llllllll}
1887 & \ldots & 2,216,030 & \ldots & 1,977,174 & \ldots & +238,856 \\
\hline
\end{array}
\end{aligned}
$$

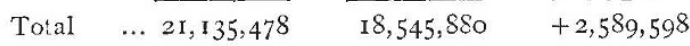

During the year of scarcity, 1878 , and that of pestilence, 1879 -for the great epidemic of unprecedentedly fatal malarial fever that year sturely deserves the name of pestilence-the net loss of population was over a million; but in the next three years this was fully recovered, and in the succeeding years large numbers were added to the population, especially in the healthy year, 1883. Thus the net gain for the ten years, notwithstanding famine and pestilence, was over two millions and a half, an increase almost unprecedented since the first census in 1853 , and doubtless the result of an unusually long succession of abundant harvests. Since i 885 , however, the increase has grown less and less rapid; and as another scarcity is now nearly due, if any trust may be placed in the average period of the recurrence of droughts in the past, it seems likely that in the next two or three years the increase may be temporarily stopped.

With these figures, and the fixed point given by the census of $\mathrm{I} 88 \mathrm{I}$, it is possible to find the probable number living at the commencement of each year from 1878 to I 888, and also the mean birth- and death-rate for each year of the ten. The census was taken on the night of February 17, 1881, and the total of the people numbered 
was $44,107,869$. In the Census Report it is, however, shown that over a million females between the ages of 5 and 20 must have escaped enumeration; and when allowance is made for them, the probable accurate total comes out 45,232,39I. During January and the first seventeen days of February the increase was II8,532; so at the beginning of I88I the population stood at 45 , I 1 3,859 . From this starting-point the following figures have been worked out :--

\begin{tabular}{|c|c|c|c|c|c|c|}
\hline Year. & & $\begin{array}{l}\text { Number living } \\
\text { at Commencement. }\end{array}$ & & Year. & & $\begin{array}{l}\text { Number living } \\
\text { Commencement. }\end{array}$ \\
\hline I 878 & $\cdots$ & $45,890,988$ & $\cdots$ & I 884 & & $46,794,604$ \\
\hline I 879 & $\ldots$ & $45,628,357$ & $\cdots$ & I 885 & $\cdots$ & $47,343,463$ \\
\hline I 880 & ... & $44,879,553$ & $\ldots$ & 1886 & $\ldots$ & $47,930,770$ \\
\hline I 881 & $\ldots$ & 45, I 13,859 & $\ldots$ & I 887 & $\ldots$ & $48,241,730$ \\
\hline 188 & $\ldots$ & $45,688,103$ & $\ldots$ & I 888 & $\ldots$ & $48,480,586$ \\
\hline
\end{tabular}

The mean number living during the ten years was $46,478,714$.

The total area of the united provinces is given in the Census Report as 106,104 square miles. The population is thus at the present time about 457 to the square mile, including in the average the Himalayan province of Kumaon, over I2,000 square miles in area, where the average density is less than 90 to the square mile. There is practically no export trade, except in agricultural produce ; hence the whole population is supported directly or indirectly by the agriculture of the province ; and there is probably no purely agricultural country in the world, except perhaps some parts of China, where so dense al population is maintained.

The birth- and death-rates and rate of increase or decrease each year, calculated on the usual basis of 1000 living, are given in the next table.

\begin{tabular}{|c|c|c|c|c|c|c|}
\hline Year. & & Birth-Rate. & & Death-Rate. & & ate of Increa \\
\hline 1878 & $\cdots$ & $35 \cdot 83$ & $\cdots$ & $4 I \cdot 57$ & $\cdots$ & -574 \\
\hline I 879 & $\cdots$ & $36 \cdot 33$ & $\cdots$ & $52 \cdot 88$ & $\cdots$ & $-16 \cdot 55$ \\
\hline I 880 & $\cdots$ & 40.54 & $\ldots$ & $35 \cdot 37$ & $\cdots$ & +5.17 \\
\hline I $88 \mathrm{I}$ & $\cdots$ & $5 \mathrm{I} \cdot 26$ & $\ldots$ & $38 \cdot 61$ & $\cdots$ & +12.65 \\
\hline 1882 & $\ldots$ & $46 \cdot 89$ & $\ldots$ & $40 \cdot 50$ & $\ldots$ & +6.39 \\
\hline 1883 & $\ldots$ & $5^{0} \cdot 32$ & $\cdots$ & $32 \cdot 78$ & $\ldots$ & +17.54 \\
\hline I 884 & $\cdots$ & $52 \cdot 97$ & $\ldots$ & $4 I \cdot 3 I$ & $\cdots$ & $+11 \cdot 66$ \\
\hline 1885 & $\cdots$ & $49 \cdot 35$ & $\cdots$ & $37^{\circ} \mathrm{O} 2$ & $\cdots$ & +1233 \\
\hline I 886 & $\cdots$ & $44^{\circ} 72$ & $\cdots$ & $38 \cdot 24$ & $\cdots$ & +6.48 \\
\hline I887 & $\cdots$ & $45 \cdot 82$ & $\cdots$ & $40 \cdot 88$ & $\cdots$ & +494 \\
\hline Mean & $\ldots$ & $45^{\circ} 40$ & & $39^{\circ} 9 \mathrm{I}$ & & $5 \cdot 49$ \\
\hline
\end{tabular}

The birth-rate, even in the worst years of the ten, was as high as in England, while in the best years it was about 50 per cent. higher. The death-rate averaged nearly forty per mille, and therefore, notwithstanding the high birth-rate, the population increased only at the rate of 5.5 per thousand per annum.

A glance at the annexed diagram will render these data more intelligible. Fig. I exhibits the movement of the total population from year to year ; and the nearly straight line, marked Fig. 2, shows what this movement would have been had it proceeded uniformly at the rate of 5.49 per mille per annum. The curve has been computed by the formula $\mathrm{P}=\mathrm{P}_{0} r_{n}$, where $u$ is counted from the beginning of 1883 , and consequently the ordinate for $1883, \mathrm{P}_{0}$, is the geometrical mean of all the ordinates of Fig. I. The differences of the ordinates of the first two curves are charted in Fig. 3, which therefore exhibits the extent to which the actual population exceeds or falls short of that given by a uniform movement. This is apparently a periodic function of the time; and if so, the period does not differ much from ten years, since the last ordinate is only slightly greater than the first. Figs. 4 and 5 represent the birth- and death rates respectively. At first sight these appear to have no relation to each other, as concomitant and opposed variations are nearly equal in numbers. The years of lowest death-rate, I 880 and I 883 , were, however, followed by the years of highest birth-rate, showing that healthy conditions conduce to fecundity as well as diminished mortality. An exception to this rule is, however, found in 1879 , which, following a healthy year, should have had a high birthrate, but was marked instead by an exceptionally low one. The year 1878 , though a dry and very healthy year, was one in which the vitality of the people reached a low ebb, owing to long-continued scarcity, approaching in some places to famine; for, though few or none actually died of starvation, millions were for many months at starvation-point.

The annual rate of increase per thousand, shown in Fig. 6, is probably the best possible measure of the general well-being of the people, combining as it does the effects of abundance or scarcity of food, which infuence the birthrate, with those of health and disease, on which the death-rate depends. Curiously enough, this index of general prosperity or the reverse is much less liable to sudden fluctuations than the birth- or death-rate alone, and yet, like the numbers represented by Fig. 3, it is apparently subject to a periodic oscillation about a mean value. The length of the period is probably something over ten years, since the last year gives a considerably greater result than the first, though it exhibits a downward tendency. It is therefore possible that the rate of increase of a primitive people, living a natural life untrammelled by too much civilization, and multiplying up to the limit of the means of subsistence, may be subjectlike the prices of grain, investigated by Mr. E. Chambers and the late Mr. Stanley Jevons, and like many other terrestrial phenomena-to a periodic variation determined by that of the energy received from the sun. Assuming that there is a variation with a period of eleven years, the rates of increase charted in Fig. 6 lead to the formula, $r=4.576+11725 \sin \left(\frac{2 \pi n}{11}+262 \frac{1}{2}^{\circ}\right)$. This formula gives the smoothly flowing curve of Fig. 6, which coincides, as fairly as may be, with the curve of actual variations. For the minimum epoch the formula gives I 878.73 , and for the maximum I884.23,--dates which fall suggestively near those of the corresponding phases of solar disturbance.

Into this interesting speculation it is impossible at present to enter further, beyond remarking, as was said at the beginning, that the increase of the population during the last ten years was probably above the average, and too rapid to be maintained. The hypothesis that it is subject to a variation in the eleven-year period leads to the result that the mean for a long term of years is only 4.576 per thousand, instead of 549 . Now, in the Report on the Census of I88I, the Census Officer, Mr. Edmund White, calculated that the population, as reported, increased only 2.33 per thousand per annum between 1853 and 1881 ; but it is pointed out that this result was vitiated by an over-estimation in 1853 , when the individual members of the population were not counted by name, but only the total number of each family was entered in the census forms. In the sixteen years from 1865 to I88I the rate of increase was 448 , and as these years included a fair proportion of good and bad, the rate of movement is probably near the truth. It differs only by a small fraction from the mean rate given by the above formula, according to which the population might be expected to double itself in 152 years, notwithstanding the already great pressure on the soil. In the same Census Report, from the distribution of the population according to age, a mean death-rate of 39.5 per mille is arrived at. This agrees sufficiently closely with the rate here found to warrant the conclusion that the corrections applied to the numbers actually registered cannot be far wrong.

Fig. 7 shows the variations of the average rainfall of the province, for which the general mean of the ten years 

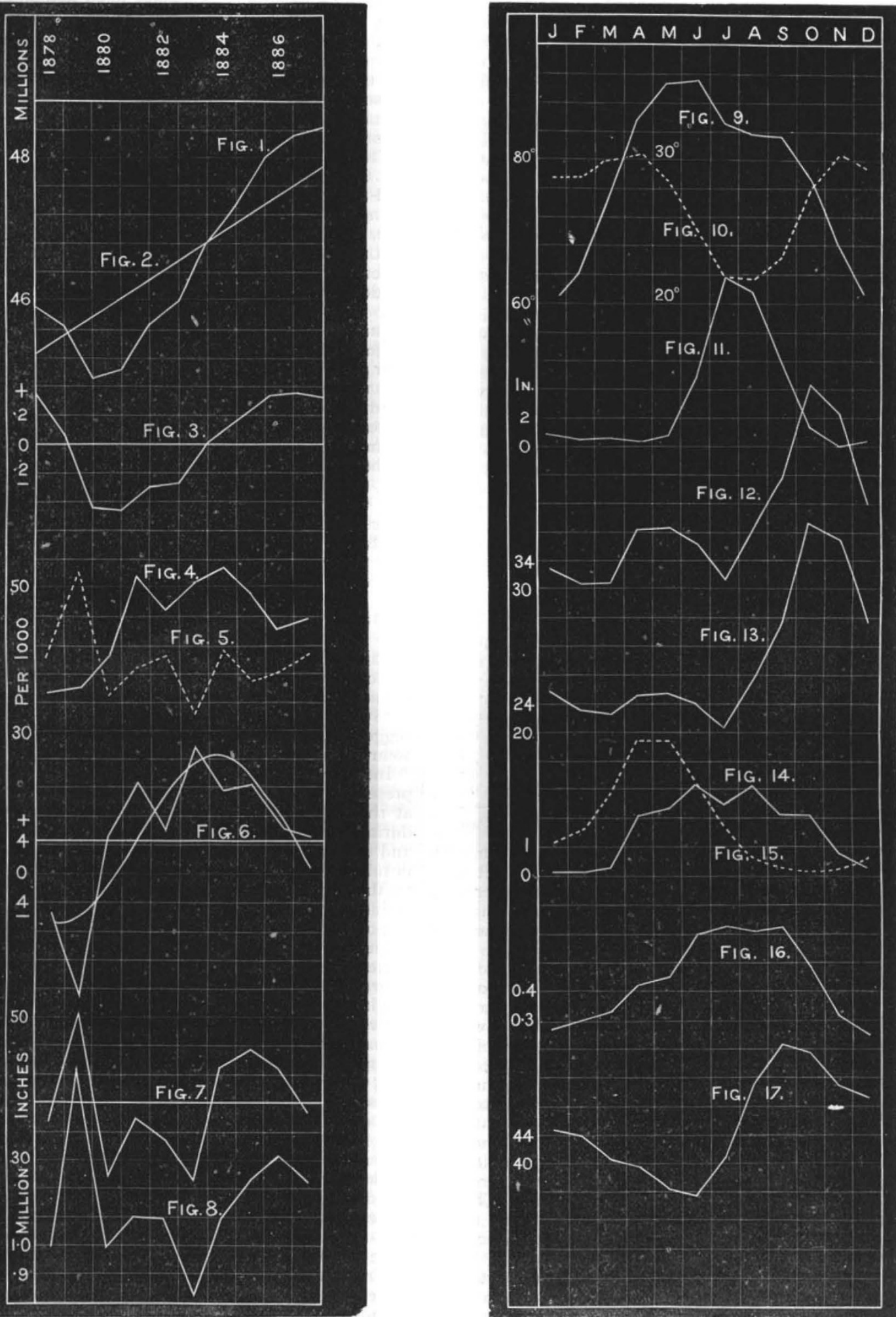
was almost exactly 38 inches. Neither the birth-rate nor the rate of increase has any distinct relation to the rainfall, but there are very evident indications of such a relation as regards the rate of mortality. The first seven years witnessed great fluctuations in the rainfall, and these were almost exactly parallel in the death-rates, the wettest years being those of greatest mortality. During the last three years, on the other hand, the death-rate increased slightly as rainfall diminished, and vice vers $\hat{a}$. Amongst the principal causes of death, cholera and small-pox vary enormously in their prevalence from year to year, these diseases being of an epidemic nature ; but the variations do not seem to be related in any way to the rainfall. On the contrary, those from endemic malarial fevers, represented by Fig. 8, follow the rainfall variations very closely, and they are the chief factors in the general mortality.

In my former article, the death-rates from various causes were compared with the prevailing meteorological conditions, not year by year, but month by month. If a similar method be adopted with the statistics of the ten years now available, the conclusions arrived at in the former paper are fully borne out as regards all their more important points, only needing, in one or two instances, slight modifications in detail.

The next table gives the total mortality for each month, computed as a rate per mille per annum, and also the rates for certain specified causes of death, which can in most cases be recognized by the recording agency. In computing these, the registered numbers have all been increased by an allowance for omissions similar to that given above.

\begin{tabular}{|c|c|c|c|c|c|c|}
\hline $\begin{array}{l}\text { Month. } \\
\text { January' }\end{array}$ & $\begin{array}{c}\text { Total } \\
\text { Mortality. } \\
\ldots \quad 32 \cdot 7 \mathrm{I}\end{array}$ & $\begin{array}{c}\text { Fevers. } \\
25^{\circ} \cdot 64\end{array}$ & $\begin{array}{c}\text { Cholera. } \\
0.08\end{array}$ & $\begin{array}{c}\text { Small- } \\
\text { pox. } \\
1 \cdot 16\end{array}$ & $\begin{array}{l}\text { Suicide. } \\
0.032\end{array}$ & $\begin{array}{c}\text { Wounds or } \\
\text { Accidents. } \\
0.236\end{array}$ \\
\hline February & $\ldots 3085$ & 22.95 & 0.08 & $x \cdot 65$ & 0.036 & 0.255 \\
\hline March & ․ 30.94 & $22 \cdot 26$ & 0.31 & $2 \cdot 7 \mathrm{r}$ & 0.062 & 0.276 \\
\hline April & ‥ $38 \cdot 26$ & $25 \% 46$ & 2.04 & 479 & 0.087 & 0.325 \\
\hline May & $\ldots 3840$ & 25.55 & $2 \cdot 32$ & 475 & 0.080 & 0.366 \\
\hline June & ․ $36 \cdot 29$ & $24^{\circ} \mathrm{I} 2$ & 3 .II & 320 & 0.083 & 0.508 \\
\hline July & $\cdots 3 \mathrm{I}^{\cdot}{ }^{4} \mathrm{I}$ & $20 \cdot 88$ & $2 \cdot 59$ & I.7I & 0.078 & 0.543 \\
\hline August & $\ldots 3^{8 \cdot 67}$ & 26.94 & 3.08 & 0.65 & 0.077 & 0.535 \\
\hline September & $\ldots 45.27$ & $34: 39$ & $2 \cdot 19$ & 0.26 & 0.084 & 0.532 \\
\hline October & ... $58 \cdot 60$ & $48 \cdot 77$ & 2.06 & 0.12 & 0.076 & 0.404 \\
\hline November & ‥ 54.67 & 46.07 & 0.79 & 0.18 & 0.050 & 0.276 \\
\hline December & ‥ 42.53 & $36 \cdot 12$ & 0.36 & 0.51 & 0.034 & 0.228 \\
\hline Year & $\cdots$ & $29^{\circ} 98$ & $1 \cdot 58$ & $I \cdot 8 I$ & 0.066 & 0.374 \\
\hline
\end{tabular}

This table shows how utterly insignificant as causes of death are cholera and small-pox, the two most dreaded diseases, by the side of fevers, which account for threefourths of the total mortality.

The monthly mean values of the three chief climatic factors for the last ten years may be compared with the preceding figures. They are :-

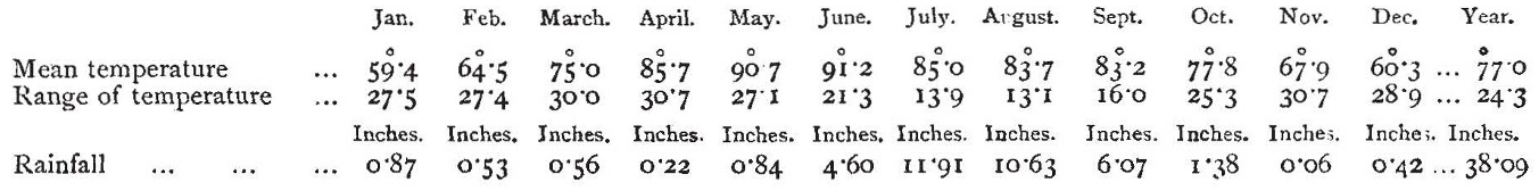

These are computed on the average of the whole province, exclusive of the higher hill stations.

The relations of the rates of mortality to these climatic causes will be best seen from the curves marked Fig. 9 to Fig. 16. The general death-rate, and that of fever mortality, which follows it closely, have two maxima in October and April or May, and two minima in July and February or March. The secondary maximum in May is a very important feature in the fever curve (Fig. I3), but rises noticeably above the preceding minimum in Fig. 12, which represents the general mortality, owing to the influence of small-pox and, to a small extent, of cholera. The fatal prevalence of fever seems to be altogether uninfluenced by the temperature (represented by Fig. 9), and its variations are almost exactly opposed in phase to those of the rainfall, shown in Fig. II; but the maxima and minima nearly coincide in time with those of the daily range of temperature (Fig. Io). These statistics therefore confirm the general experience that people are most subject to fever when the nights are chilly and the days hot. If we neglect the secondary maximum in the hot season, Figs. II and I3, representing rainfall and fever mortality respectively, will be observed to be almost identical in form, except that the latter is displaced three spaces to the right. This means that malarial fevers are directly dependent on rainfall, in their annual variation as in the variations from year to year; but it takes about three months in Northern India for the malarial conditions brought about by the rainfall (which probably depend on the growth and decay of vegetation) to attain full development. Dr. Meldrum has shown, in several of his annual reports, that in Mauritius the highest fever mortality follows the maximum rainfall at an interval of about two months, and in Northern India a parallel rule seems to hold, except that the interval is slightly longer.

The meteorological conditions predisposing to cholera are evidently heat and moisture, the disease being more prevalent than usual during the whole hot season from April to October, and dying out in the winter. The cholera curve (Fig. 14), which is drawn on a scale four times more open than that for the total mortality, has two maxima in June and August, and a secondary minimum in July. In most years the first maximum falls in April or May, but it has been thrown forward to June in the average for the last ten years by the excessive mortality of last June, when over 50,000 deaths from cholera were registered.

Regarding small-pox (Fig. 15), shown on the same enlarged scale as cholera, all the remarks in my former article hold good. This disease is at a maximum in April and May, and it diminishes rapidly during the rains, until it almost dies out in October and November. The conditions most. favourable to its spread seem to be a high wind, and very dry, or perhaps rather very dusty, air ; and the number of fatal cases may be almost exactly represented as a direct function of the wind velocity and the dryness of the air. "This result is completely in accordance with all that is known about the cause and mode of propagation of the disease.

Fig. I6 gives the annual variation of the deaths by violence, including under this head both suicides and wounds. The curve is a very smoothly flowing one, with a distinct annual minimum at the coldest time of the year, a steady rise through the dry hot season, and relatively high ordinates throughout the rainy season. The scale of the curve is ten times more enlarged than that of the cholera curve, or forty times larger than the scale of total mortality or fever; but though this magnification renders the annual variation visible, it does not reveal any irregularity except a slight increase in September, when, owing to a long "break," or the premature cessation of the rains, the weather sometimes becomes very much hotter than in July or August. This September maximum is more distinct in the suicide ratios than in those of deaths from wounds. It appears, therefore, that these fatalities from crime, instead of disease, 
are distinctly subject to climatic causes, and the explanation given in my former article, which attributes them to irritability of temper consequent on long-continued heat and moisture, is the best I can put forward.

When the birth statistics are analyzed with reference to the annual period, results equally striking and curious are brought out. The numbers registered, when tabulated month by month, corrected for the causes of error mentioned at the commencement of this article, and thrown into the form of average rates per thousand per annum, give the following table, in which also the monthly ratios, which are for nine years only, have been slightly altered sn as to make the annual mean equal to that already found for ten years:-

\begin{tabular}{|c|c|c|c|c|c|c|c|c|}
\hline \multicolumn{2}{|l|}{ Month. } & \multicolumn{2}{|l|}{ Males. } & \multicolumn{2}{|l|}{ Females. } & Total. & \multicolumn{2}{|c|}{$\begin{array}{l}\text { Number of } \\
\text { Males to } \\
\text { xoo Femal }\end{array}$} \\
\hline January & $\ldots$ & $22 \cdot 67$ & $\ldots$ & $21 \cdot 92$ & .. & 4459 & $\cdots$ & $103 \cdot 42$ \\
\hline February & $\ldots$ & $22 \cdot 3 I$ & $\ldots$ & $2 \mathrm{I} \times 53$ & $\cdots$ & $43 \cdot 84$ & $\ldots$ & $103^{\circ} 67$ \\
\hline March & $\ldots$ & $20^{\circ} 72$ & $\ldots$ & $19^{\circ} 95$ & $\cdots$ & 40.67 & $\cdots$ & 10 \\
\hline April & .. & $20 \cdot 17$ & $\ldots$ & 0 & $\ldots$ & 39.47 & $\cdots$ & 51 \\
\hline $\mathrm{Ma}$ & $\ldots$ & I $8 \cdot 46$ & $\cdots$ & 17 & $\cdots$ & $36 \cdot$ I I & $\cdots$ & 104.65 \\
\hline $\mathrm{Ju}$ & $\ldots$ & 18 & $\ldots$ & I 7 & $\cdots$ & $35^{\circ} 43$ & $\ldots$ & 104.74 \\
\hline July & $\cdots$ & $20 \cdot 80$ & $\ldots$ & $197^{\circ}$ & $\cdots$ & 40 & $\cdots$ & 59 \\
\hline August & $\ldots$ & $25: 8 I$ & $\ldots$ & 24.72 & $\cdots$ & 50 & $\cdots$ & $1044^{\circ} \mathrm{I}$ \\
\hline Sep & & $28 \cdot 85$ & $\ldots$ & $27 \cdot 86$ & $\cdots$ & $56 \cdot 71$ & $\cdots$ & IO3.55 \\
\hline $\mathrm{Oc}$ & $\cdots$ & $28 \cdot 30$ & $\ldots$ & $27.4 \mathrm{I}$ & $\cdots$ & $55^{\circ} 71$ & $\cdots$ & $103 \cdot 25$ \\
\hline No & $r \ldots$ & $25 \cdot 89$ & $\cdots$ & 25 & $\cdots$ & 04 & $\cdots$ & IO2.94 \\
\hline $\mathrm{De}$ & $r \ldots$ & $25^{\circ} 3^{6}$ & $\cdots$ & $24 \cdot 88$ & $\cdots$ & $50^{\circ} 24$ & $\cdots$ & $1015^{2}$ \\
\hline Yea & & & $\cdots$ & $22 \cdot 28$ & & 40 & & 1 \\
\hline
\end{tabular}

From the existence of the Holi festival among the Hindus, and of similar spring festivals, accompanied with lascivious songs and dances, among many barbarous tribes, as well as from the traces of such festivals still surviving in Europe, and the hints given by classical writers regarding the nature of certain annual religious mysteries performed by the early Greeks and Romans, anthropologists have thought that possibly, during prehistoric times, the human species, like the lower animals in a state of nature, had an annual pairing-time. If any traces of such a condition still survive, we may with some confidence look for them in India, where a large number of the poorer classes are chronically on the verge of starvation, and the different seasons are sufficiently marked in character to affect people differently both in body and in mind. The birth-rates in the above table, represented by Fig. 17 in the diagram, exhibit a most distinct annual variation, smoother and more uniform in character than any of the mortality curves, and with a range equal to nearly 50 per cont. of the mean value. The minimum falls in June and the maximum in September,--dates which point to a maximum of conceptions in December, and a minimum in September. "The latter month is near the end of the long and depressing hot season, when malarial influences are rapidly increasing to a maximum, the food-supply of the year is nearly exhausted, and there is the greatest tendency to suicide. The births, as well as the deaths, therefore, show that at the end of the rains the vitality and energy of the people have reached low-water mark.

In December, on the other hand, not only is the salubrity of the country greatly increased, as shown by the rapid diminution of nearly every cause of death, but food is again cheap and abundant. The crops of millet, on which the poorer classes live, are sown in July and reaped in November. During Necember and the latter half of November they are threshed out, and then is the season for paying the village functionaries and labourers their share of the produce. Consequently food is more abundant at this time of the year than at any other, and as a result of these conditions we find a large number of births the following September and October.

It thus appears that among the poorest of the population there is probably still a more or less distinct annual reproductive season, but instead of being determined by the returning warmth of spring, as must have been the case in prehistoric Europe, it follows the annual return of healthy conditions with abundant food-supply. That the Holi festival occurs in spring, instead of in December, is perhaps to be accounted for as a survival from a time when the ancestors of the Hindus lived in a colder climate.

In the last column of the table are given the monthly values of the ratio of males to females at birth. This appears to be subject to a small but distinct annual variation, with a maximum in July, and a minimum in December; but whether this is a remote and obscure physiological effect of the annual march of the seasons, or only a chance arithmetical result, I cannot say.
Allahabad, February 8.
S. A. HILL.

\section{ON THE ORBITS OF AEROLITES. 1}

MY studies have led me to the following three M propositions:

I. The meteorites which we have in our cabinets and which were seen to fall were originally (as a class, and with a very small number of exceptions), moving about the sun in orbits that had inclinations less than $90^{\circ}$; that is, their motions were direct, not retrograde.

2. The reason why we have only this class of stones in our collections is not one wholly or even mainly dependent on the habits of men; nor on the times when men are out of doors; nor on the places where men live; nor on any other principle of selection acting at or after the arrival of the stones at the ground. Either the stones which are moving in the solar system across the earth's orbit move in general in direct orbits; or else for some reason the stones which move in retrograde orbits do not in general come through the air to the ground in solid form.

3. The perihelion distances of nearly all the orbits in which these stones moved were not less than $0^{\prime} 5$ nor more than $I^{\circ} \mathrm{O}$, the earth's radius vector being unity.

The first and thirds propositions are limited strictly by their terms to the meteorites from stone-falls actually witnessed, and also represented by specimens in some one or more of existing collections. The investigations that have led to them have been limited to the same stonefalls. This is not because any line of separation is sus. pected to exist astronomically between the stone-furnishing and detonating meteors, or even between them and the shooting stars, but because, for manifest reasons, any facts established about these stones have a greater value than similar facts about meteors from which no stones have been secured.

About 265 observed falls are represented by specimens in existing collections. The history of these falls I have searched out with no little pains, so far as the material for such history could be found in books accessible to me. Every direct statement and every indirect indication which I have obtained about the paths of these meteors through the air have been carefully considered, and their meaning and value duly estimated The determination of the path of a stone-furnishing meteor through the air is greatly aided by the fact that we know at once one point of the trajectory, viz.: the point where the stone strikes the ground. To this fact may usually be added another, viz: that some of the observations are by persons near the place of fall, and hence their statements of direction, so far as we may trust them, have peculiar significance. In individual cases it will be found that not much reliance can be placed upon the asserted direction of the meteor's motion. But when the results are all

I "Upon the relation which the former Orbits of those Meteorites that are H. A. Newton. (From the American Fournal of Science, July i 888.) 